\section{Choroidal thickness measurements in children with isolated growth hormone deficiency}

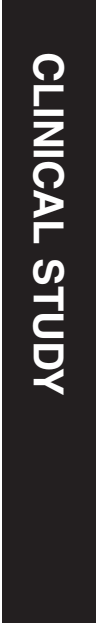

${ }^{1}$ Department of Ophthalmology, Gazi University Medical Faculty, Ankara, Turkey

${ }^{2}$ Department of Pediatric Endocrinology, Gazi University Medical Faculty, Ankara, Turkey

Correspondence: NG Yalçın, Department of Ophthalmology, Vezirköprü State Hospital, Vezirköprü, Samsun, Turkey Tel: +90 5334159009 E-mail: gokcen_dnz@ hotmail.com

Received: 11 April 2017 Accepted in revised form: 11 July 2017 Published online: 15 September 2017

\author{
Abstract \\ Purpose The aim of this study was to \\ determine the choroidal thickness measurement \\ values in cases with isolated growth hormone \\ deficiency (IGHD), to compare them with the \\ healthy control group by using enhanced depth \\ imaging optical coherence tomography (EDI- \\ OCT), and to evaluate the effect of growth \\ hormone (GH) treatment on choroid. \\ Patients and methods In this study, 23 cases \\ who were diagnosed with IGHD as a study \\ group and 46 healthy subjects as a control \\ group were included. All patients and \\ controls underwent a complete \\ ophthalmologic examination, including an \\ examination with EDI-OCT. Choroidal \\ thickness (CT) was measured at the fovea and \\ at $\mathbf{1 0 0 0} \mu \mathrm{m}$ intervals from the foveal center in \\ both temporal and nasal directions. \\ Results The mean subfoveal choroidal \\ thickness (SFCT) was $329.04 \pm 88.49 \mu \mathrm{m}$ in the \\ cases with IGHD and $365.35 \pm 50.48 \mu \mathrm{m}$ in the \\ control group $(P=0.033)$. The mean $\mathrm{CT}$ at \\ temporal 1 and $2 \mathrm{~mm}$ were thinner in the \\ IGHD group than that of control group \\ ( $P=0.033$ and $P=0.043$, respectively). Nasal \\ quadrant measurements were also found to \\ be thinner in the IGHD cases than that of \\ control group, but the difference was not \\ statistically significant. We found a significant \\ positive correlation between pubertal staging \\ and SFCT ( $\left.r_{\mathrm{s}}=0.607, P=0.006\right)$. There was no \\ statistically significant difference in CT \\ values of the study group between before and \\ 12 months after $\mathrm{GH}$ treatment $(P>\mathbf{0 . 0 5})$. \\ Conclusion This study shows patients with \\ IGHD has a thinner CT when compared with \\ healthy pediatric cases. GH treatment seems \\ to be not associated with the choroidal \\ development. \\ Eye (2018) 32, 364-369; doi:10.1038/eye.2017.194; \\ published online 15 September 2017
}

NG Yalcin¹, Z Aktas, O Yuce², GDG Ikiz, $M$ Hasanreisoglu ${ }^{1}$ and $A$ Bideci ${ }^{2}$

\section{Introduction}

Growth hormone deficiency is a condition with clinical, biochemical, auxological, and metabolic abnormalities in which the production of growth hormone (GH)-dependent hormones and growth factors are decreased as a result of insufficiency or deficiency of GH secretion with a complex etiology. ${ }^{1}$ Isolated growth hormone deficiency (IGHD) can be defined as childhood growth retardation as a consequence of decreased GH that is not always accompanied by a lack of other pituitary hormone deficiencies or an organic lesion. ${ }^{2}$ In a previous report, $\mathrm{GH}$ was said to have an effect on ocular development with endocrine, autocrine, and/or paracrine roles and also the eye was accepted as a target site for $\mathrm{GH} .^{3}$ Many different ocular abnormalities have been reported in patients with GH deficiency. ${ }^{4-8}$

$\mathrm{GH}$ has been shown to have angiogenic effects and retinal cells are known as a domain of local growth factors, including insulin-like growth factor-I (IGF-I). ${ }^{9}$ Reduced retinal vascularization in Laron syndrome (GH insensitivity syndrome) demonstrated that GH-IGF-I axis is crucial for normal vascularization of the human retina. ${ }^{10}$

The choroid accounted for most of the ocular blood flow and supplied the outer retina, consisting of choroiocapillaris and vessel layers. ${ }^{11}$ Although choroid has a rich vasculature and is a possible target for angiogenic factors, no report has demonstrated any relationship between the choroid and GH-IGF-I.

Imaging of the choroid has been challenging even with optical coherence tomography (OCT) because of the limited penetration of the wavelength of the light source. ${ }^{12}$ A newer technique using standard spectral-domain OCT (SD-OCT) named 'enhanced depth imaging 
optical coherence (EDI-OCT)' provided possibility for choroidal visualization. ${ }^{13}$

The aim of this study was to evaluate choroidal thickness (CT) in children with IGHD, to compare it with those of healthy subjects, and to find out whether choroidal thickness is affected by the recombinant human $\mathrm{GH}$ treatment.

\section{Materials and methods}

Twenty-three patients diagnosed with IGHD at the Department of Pediatric Endocrinology of Gazi University Medical Faculty between January 2012 and September 2013 were included in the study. Forty-six healthy children carefully matched for age, gender, body mass index (BMI), and pubertal stage were chosen as a control group. This study was conducted in accordance with the tenets of the Declaration of Helsinki, and written informed consent was obtained from all subjects. The study protocol was approved by the local institutional review board and ethics committee.

Exclusion criteria for the study were: a history of preterm or small for gestational age birth, a diagnosis of cardiovascular disease, thyroid disease as well as hepatic or renal disease, obesity, current hypertension, and the presence of chromosomal abnormalities. The detailed physical examination was performed in all subjects. The anthropometric measurements included weight, height, and BMI. Pubertal staging was assessed by Tanner stage according to breast development in girls and genital development in boys. ${ }^{14}$ Bone age was evaluated by using the Greulich and Pyle atlas. Routine biochemical test, complete blood count, as well as thyroid function test and serum tissue transglutaminase antibodies were obtained from all patients. IGF-I and IGFBP-3 levels were also measured at baseline. GH stimulation test with L-DOPA and Klonidin was performed for each patient. Peak GH response after two stimulation tests below $10 \mu \mathrm{g} / 1$ was accepted as inadequate. Finally, the diagnosis of IGHD was established by the clinical, auxological, and biochemical criteria of the GH Research Society. ${ }^{15}$ After the diagnosis, recombinant human $\mathrm{GH}$ treatment was started at the initial daily dose of $0.025 \mathrm{mg} / \mathrm{kg}$ and dose adjustment was made during the study. All patients were referred to ophthalmology clinic from the Department of Pediatric Endocrinology for ophthalmologic examination.

\section{Ophthalmologic examination}

All patients and controls underwent a complete ophthalmologic examination, including an autorefractometer (RM8900; Topcon, Tokyo, Japan), bestcorrected visual acuity (BCVA) measurement with a 6-m Snellen eye chart, slit-lamp biomycroscopy, fundus examination, and intraocular pressure measurement. Subjects with high myopia or hyperopia $(>+6$ or -6 diopters of spherical equivalent), BCVA $<20 / 25$, amblyopia, and any ocular disease were not included in the study.

Subjects underwent an examination with Heidelberg Spectralis-OCT (Spectralis, Heidelberg Engineering, Heidelberg, Germany) for the measurement of the CT. EDI-OCT images were obtained as the same technique reported by Spaide et al. ${ }^{12}$ Images were acquired by the same experienced technician. OCT device was brought closer to the eye to get images invertedly. The average of 100 scans using the automatic averaging and eye tracking features were used to get these $9 \mathrm{~mm}$ horizontal images. ${ }^{16}$ All patients were evaluated at baseline and after 12 months of GH treatment to determine any effect of treatment on the CT. At the follow-up visits, patients with poor compliance with treatment were not take into account while analyzing first-year effect of GH treatment on ocular parameters.

The choroid was measured manually using caliper tool by one clinician (NGY). Measurement was made between the highly reflective layer corresponding to the retinal pigment epithelium (RPE)/Bruch complex and the sclerochoroidal interface. The CT was measured from the foveal center and $1000 \mu \mathrm{m}$ apart, starting from the foveal center, in the nasal and temporal directions for 4 other measurements. ${ }^{17}$ Examinations were performed at the same interval of the day (1000-1200 h) in order to exclude the effect of diurnal change at CT. The value of CT at this time interval was relatively high according to the rest of the working time. ${ }^{18}$

\section{Statistical analysis}

Data obtained from the study were recorded using Excel for Windows (version 2010, Microsoft, Redmond, WA, USA) and statistical analyses were performed using the Statistical Package for the Social Sciences for Windows (version 15.0, SPSS, Chicago, IL, USA). Right eyes of subjects were selected for statistical analysis because there was no difference between the measurements of the right and the left eyes. All groups were tested for normality using the Kolmogorov-Smirnov test. Continuous variables were computed as mean $\pm \mathrm{SD}$ and median (min-max) where applicable. Differences between groups were assessed using independent samples $t$-test.

Differences between values before and after GH treatment were evaluated using paired samples $t$-test. The degree of correlation between the values was evaluated by Pearson's or Spearman's correlation coefficients where appropriate. The statistical level of significance was set to $P<0.05$. 


\section{Results}

The demographic, clinical, and ophthalmologic parameters of all subjects are shown in Table 1 . The BCVAs of all subjects were $6 / 6$.

There was a strong positive correlation between the mean subfoveal choroidal thickness (SFCT) of the right eye and the left eye (Spearman's correlation test, $P<0.01$, $r=0.906)$. The mean $K$ average values of the patients $(43.40 \pm 1.61 \mathrm{D})$ was similar to the mean $K$ average values of the control group $(43.80 \pm 1.49 \mathrm{D})(P=0.90)$. Mean SFCT was $329.04 \pm 88.49 \mu \mathrm{m}$ in the study group and $365.35 \pm 50.48 \mu \mathrm{m}$ in the control group $(P=0.033)$. In both groups, CT was reduced in nasal direction and reached minimum level at $2000 \mu \mathrm{m}$ apart from the fovea center nasally (Figure 1). Mean SFCT and thicknesses of other 4 region of both groups were summarized in Table 2 .

All measurements of CT were decreased in IGHD patient group than that of control group. Although there was a slight decrease in the thicknesses of nasal 1 and $2 \mathrm{~mm}$ of the patient group, a comparison of the two groups showed no statistically significant difference only in terms of the measurements of these two localizations.

Correlation coefficients between SFCT and age, height, BMI, pubertal staging, and biochemical values in patients with IGHD were analyzed and are shown in Table 3. There was a significant positive correlation between pubertal staging and SFCT $\left(r_{\mathrm{S}}=0.607\right)$ (Figure 2). Other parameters and SFCT did not show any correlation.

There was no statistically significant change in CT values of the study group before and 12 months after the GH treatment $(P>0.05)$. Mean SFCT was $329.04 \pm 88.49 \mu \mathrm{m}$ at pretreatment visit, whereas mean SFCT was altered to $326.20 \pm 85.93 \mu \mathrm{m}$ at posttreatment final visit $(P=0.812)$. The $\mathrm{CT}$ of temporal region was $321.22 \pm 76.15 \mu \mathrm{m}$ at $1 \mathrm{~mm}$ distance from foveal center, and $318.17 \pm 69.08 \mu \mathrm{m}$ at $2 \mathrm{~mm}$ distance from foveal center before treatment. These values changed to $337.76 \pm 77.46 \mu \mathrm{m}$ and $317.06 \pm 85.09 \mu \mathrm{m}$ after treatment, respectively $(P=0.291$ and $P=0.956$, respectively). For nasal localizations, the CT was $299.26 \pm 90.04 \mu \mathrm{m}$ at $1 \mathrm{~mm}$ apart from foveal center and $290.60 \pm 94.59 \mu \mathrm{m}$ at $2 \mathrm{~mm}$ apart from foveal center before treatment. At posttreatment final visit, these values altered to $290.60 \pm 94.59 \mu \mathrm{m}$ for nasal $1 \mathrm{~mm}$ and $239.09 \pm 87.81 \mu \mathrm{m}$ for nasal $2 \mathrm{~mm}$ ( $P=0.599$ and $P=0.608$, respectively).

\section{Discussion}

$\mathrm{GH}$ and $\mathrm{GH}$ receptor gene expression has been reported in the developing neural retina in rats, chickens, and mice. ${ }^{19}$ In studies that show relationship between GH and cornea, GH was said to have an effect on postnatal growth of the eye via IGF-I production. ${ }^{7,20,21} \mathrm{GH}$ was
Table 1 Demographic, auxological, and ophthalmologic parameters of subjects

\begin{tabular}{lccl}
\hline Parameters & Patients $(\mathrm{n}=23)$ & Control $(\mathrm{n}=46)$ & P-value \\
\hline Age (year) & $12.57 \pm 2.33$ & $11.43 \pm 3.26$ & $0.143^{\mathrm{a}}$ \\
Sex (F/M) & $12 / 11$ & $28 / 18$ & $0.49^{\mathrm{b}}$ \\
Height (cm) & $131.29 \pm 11.83$ & $143.1 \pm 12.79$ & $\mathbf{0 . 0 0 1}^{\mathrm{a}}$ \\
Weight (kg) & $35.07 \pm 12.15$ & $37.63 \pm 10.3$ & $0.395^{\mathrm{a}}$ \\
BMI & $19.75 \pm 4.52$ & $18 \pm 2.46$ & $0.052^{\mathrm{a}}$ \\
Pubertal staging & $2(1-3)$ & $2(1-5)$ & $0.054^{\mathrm{b}}$ \\
IOP (mm Hg) & $16.26 \pm 2.97$ & $15.30 \pm 2.55$ & $0.169^{\mathrm{a}}$ \\
SE & $-0.02(-2.00$ to 4.75) & $-0.16(-3.62$ to 2.75) & $0.768^{\mathrm{c}}$ \\
\hline
\end{tabular}

Abbreviations: BMI, body mass index; F, female; IOP, intraocular pressure; M, male; SE, spherical equivalent. 'Independent samples $t$-test. ${ }^{b}$ Pearson's $\chi^{2}$ test. 'Mann-Whitney $U$-test. Bold value shows statistically significant $P$-value $(P<0.05)$.

found in the vitreous of rat eyes in immunochemical studies. ${ }^{22,23}$ In addition, GH and GH receptors have been shown in retinal ganglion cells. Consequently, most of the previous studies relevant with IGHD were focused on the retina. ${ }^{4,8,24}$ Normal macular thickness and decreased retinal fiber layer thickness were found to be associated with IGHD according to these studies.

Although the mechanisms by which $\mathrm{GH}$ affects angiogenesis are not exactly known, GH has a role in retinal angiogenesis beside its influence on neural development. After birth, little or no vascularization occurs and most of the retinal vascularization happens during fetal period. ${ }^{24}$ This process is regulated by several local produced growth factors as a response to hypoxia. Hormones and factors in circulation except GH alone affect the production and action of these local factors. ${ }^{25,26}$ IGF-2 is believed to be more influential than IGF-I for ocular development in fetus. ${ }^{27}$ In clinical studies, effect of deficiency of GH on retinal vascularization was demonstrated as decreased vascular branching points. ${ }^{4,25}$ Although these mentioned studies explored $\mathrm{GH}$ in retinal development, there were no previous published data about the relationship between GH and choroid. Choroidal layer was one of the areas in which GH and GH recombinant mRNA were identified in chick embryo. ${ }^{28-30}$ Furthermore, the choroid nourishes the outer layers of the retina and is rich in blood vessels. ${ }^{31}$ As a consequence, the choroid may be a pathway for $\mathrm{GH}$ in reaching retina and may be an action site for $\mathrm{GH}$. To the best of our knowledge, this is the first study to explore $\mathrm{GH}$ effect on the choroid in a clinical study.

Visualization and evaluation of the choroid was performed with B-scan ultrasonography and indocyanine green angiography (ICG) before clinical use of SD-OCT. ${ }^{32}$ Currently, EDI-OCT has become a frequently used method for evaluation of the choroid. It has been found to be more effective in terms of the visualization of the choroid and gives precious information about choroidal morphology in healthy eye and various diseases. ${ }^{17}$ Because of the noninvasive and rapid nature of the 

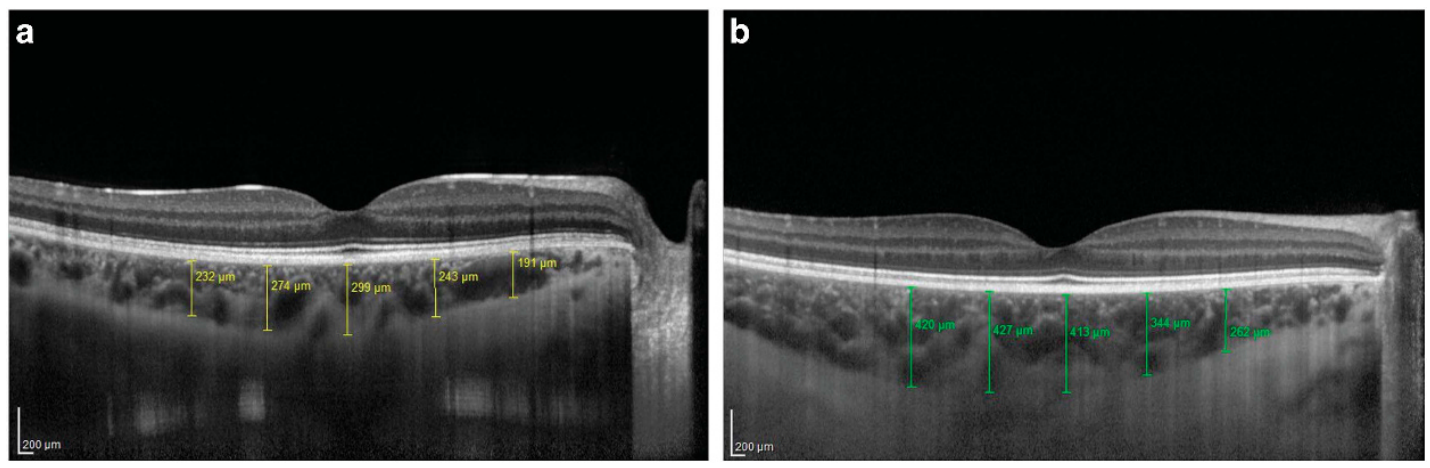

Figure 1 (a) Decreased choroidal thickness in an IGHD patient. (b) Choroidal thickness in a healthy control group patient.

Table 2 Measurements of choroidal thickness at five locations

\begin{tabular}{lccc}
\hline CT $(\mu \mathrm{m})$ & \multicolumn{2}{c}{ Groups } & P-value \\
\cline { 2 - 3 } & Patients $(\mathrm{n}=23)$ & Control $(\mathrm{n}=46)$ & \\
\hline Subfoveal & $329.04 \pm 88.49$ & $365.35 \pm 50.48$ & $\mathbf{0 . 0 3 3}$ \\
Temporal 1 mm & $321.22 \pm 76.15$ & $358.96 \pm 63.32$ & $\mathbf{0 . 0 3 3}$ \\
Temporal 2 mm & $318.17 \pm 69.08$ & $352.04 \pm 61.96$ & $\mathbf{0 . 0 4 3}$ \\
Nasal 1 mm & $299.26 \pm 90.04$ & $304.89 \pm 54.34$ & 0.747 \\
Nasal 2 mm & $235.30 \pm 76.32$ & $237.52 \pm 53.36$ & 0.889 \\
\hline
\end{tabular}

andependent samples $t$-test. Bold value shows statistically significant $P$-value $(P<0.05)$.

Table 3 Correlation coefficients between SFCT and age, height, BMI, pubertal staging, and biochemical values

\begin{tabular}{lcc}
\hline & Correlation coefficients & P-value \\
\hline Age & 0.247 & $0.256^{\mathrm{a}}$ \\
Height age & 0.380 & $0.109^{\mathrm{a}}$ \\
Height & 0.382 & $0.107^{\mathrm{a}}$ \\
BMI & 0.209 & $0.390^{\mathrm{a}}$ \\
Pubertal staging & 0.607 & $\mathbf{0 . 0 0 6}^{\mathrm{b}}$ \\
IGF-1 & -0.062 & $0.801^{\mathrm{a}}$ \\
IGF BP3 & 0.000 & $0.999^{\mathrm{a}}$ \\
\hline
\end{tabular}

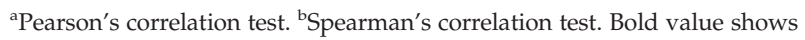
statistically significant $P$-value $(P<0.05)$.

examination of EDI-OCT, it has also been used in pediatric population. ${ }^{33-36}$ In these studies mean SFCT ranged between 314 and $348 \mu \mathrm{m}$ in healthy children. In the current study, we found mean SFCT (365.35) higher than that. On the other hand, Tenlik et $a l^{37}$ also reported higher mean SFCT $(388 \mu \mathrm{m})$ in healthy Turkish children. Thus, our data might be interpreted as a consequence of an ethnical difference on CT.

Furthermore, we found IGHD patients had lower CT than control group in subfoveal and temporal localization. Normally, CT was decreased in both directions but more nasally. ${ }^{38}$ Therefore, in this study we may not have found a significant difference between the study group and the control group, although we observed

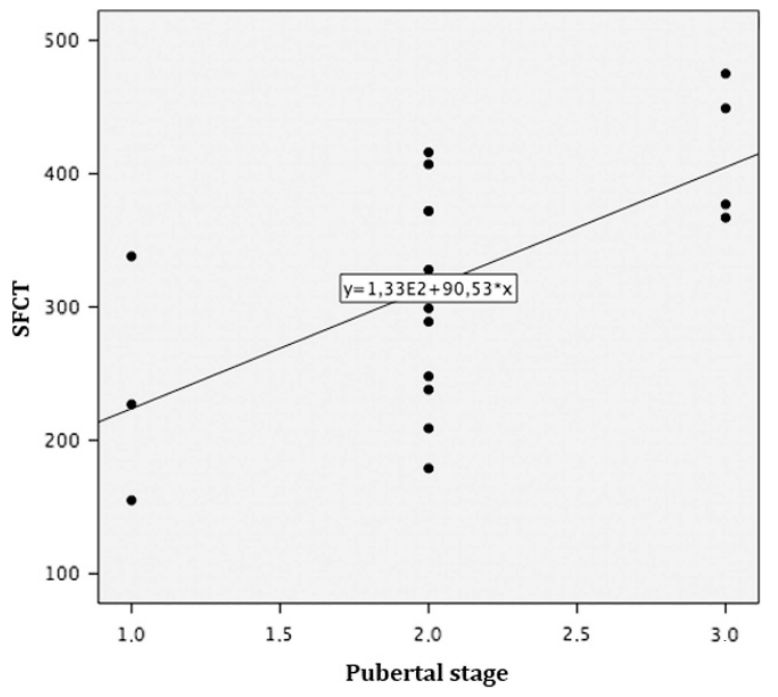

Figure 2 The correlation graphic related with the subfoveal choroidal thickness and the pubertal stage.

a slight decrease in the IGHD group in the nasal region. As known from the literature, axial length and choroidal volume correlated inversely with each other. ${ }^{39}$ Thinning of the choroid may be a result of passive stretch mechanism with eye growth. As opposed to this hypothesis, Baudet et al ${ }^{19}$ found decreased ocular axial length in $\mathrm{GH}$ receptor gene disrupted mice. Also, in early childhood CT was found to be increased until 12 years on average. It was hypothesized that thickening of the choroid may be a result of normal growth of the connective and vascular tissue. ${ }^{33}$ According to these data, lower CT in IGHD patients in our study can be explained with the retardation of the eye growth in IGHD independently of the effect of GH on axial length. Thus, whether the GH effect on the choroid is independent of the influence of $\mathrm{GH}$ on ocular growth retardation cannot be inferred.

Age and CT were found to be negatively correlated with each other in adult people. ${ }^{39}$ However in pediatric population the correlation between age and $\mathrm{CT}$ is controversial. ${ }^{33,36,40}$ In our study, age and CT correlated 
positively, although it was statistically insignificant. As the ocular growth might be disrupted in IGHD, the difference may not be statistically significant.

We found significant medium-degree positive correlation between only pubertal stage and CT. Li et al ${ }^{41}$ found that CT was increased only in girls with puberty maturity. This is probably because pubertal stage is a part of growth, and in our study CT was higher in advanced stages of puberty.

Regarding the impact of GH treatment on $\mathrm{CT}$, we found $\mathrm{GH}$ treatment had no effect on CT. This finding may indicate that GH has no effect on choroid in postnatal period. The mean age of our study group population was 12 years, and this is the age when CT is expected to reach almost its final adult values. ${ }^{33}$ This information may be an explanation of why GH treatment did not seem to affect choroidal development in this study.

Our study has several limitations. The number of patients was relatively low. On the other hand, our follow-up period was 12 months compared with another published study in which significant increase in CT occurred in at least 18 months. ${ }^{34}$ Our 1-year follow-up may be inadequate to observe choroidal growth and to detect any change in CT.

In conclusion, we showed decreased CT in IGHD compared with healthy subjects and GH treatment seems to have no effect on CT. The current study indicates that pubertal stage is well correlated with CT. Our study may be a guide for further studies to clarify GH effect on choroid. Future controlled longitudinal studies should be planned to shed light on these points.

\section{Summary}

What was known before

- Decreased vascular branching points as reduced retinal vascularization was demonstrated in IGHD. Decreased retinal fiber layer thickness was found to be associated with IGHD. Beside retina, choroid is a possible target for angiogenic factors, though there was no declaratory report on the relationship between choroid and GH-IGF-1.

What this study adds

- CT was decreased in IGHD compared with healthy subjects. GH treatment seems to have no effect on CT. The pubertal stage is positively well correlated with CT.

\section{Conflict of interest}

The authors declare no conflict of interest.

\section{References}

1 Argente J, Abusrewil SA, Bona G, Chiarelli F, Kelnar CJ, Skordis $\mathrm{N}$ et al. Isolated growth hormone deficiency in children and adolescents. J Pediatr Endocrinol Metab 2001; 14 (Suppl 2): 1003-1008.

2 Hernández LM, Lee PD, Camacho-Hübner C. Isolated growth hormone deficiency. Pituitary 2007; 10: 351-357.

3 Harvey S, Baudet ML, Sanders EJ. Growth hormone and developmental ocular function: clinical and basic studies. Pediatr Endocrinol Rev 2007; 5: 510-515.

4 Hellström A, Svensson E, Carlsson B, Niklasson A, Albertsson-Wikland K. Reduced retinal vascularization in children with growth hormone deficiency. J Clin Endocrinol Metab 1999; 84: 795-798.

5 Collett-Solberg PF, Liu GT, Satin-Smith M, Katz LL, Moshang T Jr. Pseudopapilledema and congenital disc anomalies in growth hormone deficiency. J Pediatr Endocrinol Metab 1998; 11: 261-265.

6 Parentin F, Tonini G, Perissutti P. Refractive evaluation in children with growth defect. Curr Eye Res 2004; 28: 11-15.

7 Parentin F, Pensiero S. Central corneal thickness in children with growth hormone deficiency. Acta Ophthalmol 2010; 88: 692-694.

8 Nalcacioglu-Yuksekkaya P, Sen E, Yilmaz S, Elgin U, Gunaydin S, Aycan Z. Decreased retinal nerve fiber layer thickness in patients with congenital isolated growth hormone deficiency. Eur J Ophthalmol 2014; 24: 873-878.

9 Sanders EJ, Harvey S. Growth hormone as an early embryonic growth and differentiation factor. Anat Embryol (Berl) 2004; 209: 1-9.

10 Hellström A, Carlsson B, Niklasson A, Segnestam K, Boguszewski M, de Lacerda L et al. IGF-I is critical for normal vascularization of the human retina. J Clin Endocrinol Metab 2002; 87: 3413-3416.

11 Riva CE, Alm A, Pournaras CJ. Ocular circulation. In: Kaufman PL, Alm A (eds). Adler's Physiology of the Eye, 11th ed. Saunders/Elsevier: Edingburg, 2011 pp 243-332.

12 Spaide RF, Koizumi H, Pozonni MC. Enhanced depth imaging spectral-domain optical coherence tomography. Am J Ophthalmol 2008; 146: 496-500.

13 Povazay B, Hermann B, Unterhuber A, Hofer B, Sattmann H, Zeiler $\mathrm{F}$ et al. Three-dimensional optical coherence tomography at $1050 \mathrm{~nm}$ versus $800 \mathrm{~nm}$ in retinal pathologies: enhanced performance and choroidal penetration in cataract patients. J Biomed Opt 2007; 12: 041211.

14 Marshall WA, Tanner JM. Variations in pattern of pubertal changes in girls. Arch Dis Child 1969; 44: 291-303.

15 Growth Hormone Research Society. Consensus guidelines for the diagnosis and treatment of growth hormone $(\mathrm{GH})$ deficiency in childhood and adolescence: summary statement of the GH Research Society. J Clin Endocrinol Metab 2000; 85: 3990-3993.

16 Margolis R, Spaide RF. A pilot study of enhanced depth imaging opticalcoherence tomography of the choroid in normal eyes. Am J Ophthalmol 2009; 147: 811-815.

17 Karaca EE, Ekici F, Yalçın NG, Çiftçi TU, Özdek Ş. Macular choroidal thickness measurements in patients with obstructive sleep apnea syndrome. Sleep Breath 2015; 19: 335-341.

18 Tan CS, Ouyang Y, Ruiz H, Sadda SR. Diurnal variation of choroidal thickness in normal, healthy subjects measured by spectral domain optical coherence tomography. Invest Ophthalmol Vis Sci 2012; 53: 261-266.

19 Baudet ML, Hassanali Z, Sawicki G, Lis EO. Growth hormone action in the developing neural retina: a proteomic analysis. Proteomics 2008; 8: 389-401. 
20 Ciresi A, Amato MC, Morreale D, Lodato G, Galluzzo A, Giordano C. Cornea in acromegalic patients as a possible target of growth hormone action. Endocrinol Invest 2011; 34: 30-35.

21 Nalcacioglu-Yuksekkaya P, Sen E, Elgin U, Hocaoglu M, Ozturk F, Yilmaz SA et al. Corneal properties in children with congenital isolated growth hormone deficiency. Int J Ophthalmol 2014; 7: 317-320.

22 Beharry KD, Modanlou HD, Hasan J, Gharraee Z, Abad-Santos P, Sills JH et al. Comparative effects of early postnatal ibuprofen and indomethacin onVEGF, IGF-I, and GH during rat ocular development. Invest Ophthalmol Vis Sci 2006; 47: 3036-3043.

23 Modanlou HD, Gharraee Z, Hasan J, Waltzman J, Nageotte S, Beharry KD. Ontogeny of VEGF, IGF-I, and GH in neonatal rat serum, vitreous fluid, and retina from birth to weaning. Invest Ophthalmol Vis Sci 2006; 47: 738-744.

24 Pereira-Gurgel VM, Faro AC, Salvatori R, Chagas TA, Carvalho-Junior JF, Oliveira CR et al. Abnormal vascular and neural retinal morphology in congenital lifetime isolated growth hormone deficiency. Growth Horm IGF Res 2016; 30-31: 11-15.

25 Folkman J. Clinical applications of research on angiogenesis. N Engl J Med 1995; 333: 1757-1763.

26 Smith LEH, Kopchick JJ, Chen W. Essential role of growth hormone in ischemia-induced retinal neovascularisation. Science 1997; 276: 1706-1709.

27 Cuthbertson RA, Beck F, Senior PV, Haralambidis J, Penschow JD, Coghlan JP. Insulin-like growth factor II may play a local role in the regulation of ocular size. Development 1989; 107: 123-130.

28 Takeuchi S, Haneda M, Teshigawara K, Takahashi S. Identification of a novel $\mathrm{GH}$ isoform: a possible link between $\mathrm{GH}$ and melanocortin systems in the developing chicken eye. Endocrinology 2001; 142: 5158-5166.

29 Harvey S, Johnson CDM, Sanders EJ. Growth hormone in neural tissues of the chick embryo. J Endocrinol 2001; 169: 487-498.

30 Garcia-Aragon J, Lobie PE, Muscat GEO, Gobius KS, Norstedt G, Waters MJ. Prenatal expression of growth hormone $(\mathrm{GH})$ receptor/binding protein in the rat: a role for
GH in embryonic and fetal development? Development 1992; 114: 869-876.

31 Saude T. The retina. In: Saude T (ed). Ocular Anatomy and Physiology. Blackwell Scientific Publications: London, UK, 1993, pp 53-65.

32 Karaca EE, Özdek Ş, Yalçin NG, Ekici F. Reproducibility of choroidal thickness measurements in healthy Turkish subjects. Eur J Ophthalmol 2014; 24: 202-208.

33 Read SA, Collins MJ, Vincent SJ, Alonso-Caneiro D. Choroidal thickness in childhood. Invest Ophthalmol Vis Sci 2013; 54: 3586-3593.

34 Read SA, Alonso-Caneiro D, Vincent SJ, Collins MJ. Longitudinal changes in choroidal thickness and eye growth in childhood. Invest Ophthalmol Vis Sci 2015; 56: 3103-3112.

35 Herrera L, Perez-Navarro I, Sanchez-Cano A, Perez-Garcia D, Remon L, Almenara C et al. Choroidal thickness and volume in a healthy pediatric population and its relationship with age, axial length, ametropia, and sex. Retina 2015; 35: 2574-2583.

36 Park KA, Oh SY. Choroidal thickness in healthy children. Retina 2013; 33: 1971-1976.

37 Tenlik A, Gürağaç FB, Güler E, Dervişoğulları MS, Totan Y. Choroidal thickness measurement in healthy pediatric population using Cirrus HD optical coherence tomography. Arq Bras Oftalmol 2015; 78: 23-26.

38 Wong IY, Koizumi H, Lai WW. Enhanced depth imaging optical coherence tomography. Ophthalmic Surg Lasers Imaging 2011; 42: 75-84.

39 Barteselli G, Chhablani J, El-Emam S, Wang H, Chuang J, Kozak I et al. Choroidal volume variations with age, axial length, and sex in healthy subjects: a three-dimensional analysis. Ophthalmology 2012; 119: 2572-2578.

40 Bidaut-Garnier M, Schwartz C, Puyraveau M, Montard M, Delbosc B, Saleh M. Choroidal thickness measurement in children using optical coherence tomography. Retina 2014; 34: 768-774.

41 Li XQ, Jeppesen P, Larsen M, Munch IC. Subfoveal choroidal thickness in 1323 children aged 11 to 12 years and association with puberty: the Copenhagen Child Cohort 2000 Eye Study. Invest Ophthalmol Vis Sci 2014; 55: 550-555. 